\title{
PERANCANGAN MONITORING SUHU TRANSFORMATOR TENAGA 150 / 20 KV BERBASIS ARDUINO MEGA 2560
}

\author{
Bambang Winardi*) \\ Departemen Teknik Elektro, Universitas Diponegoro, \\ Jl. Prof. Soedarto, SH, Kampus Undip Tembalang, Semarang, Indonesia 50275 \\ *)E-mail: bbwinar@gmail.com
}

\begin{abstract}
Abstrak
Gangguan pada trafo dapat menyebabkan rusaknya dan menurunnya kinerja dari trafo. Contoh penyebab dari rusaknya trafo adalah overload dan beban tidak seimbang. Overload terjadi karena beban yang terpasang pada trafo melebihi kapasitas maksimum dari trafo dimana arus beban melebihi arus beban penuh dari trafo. Trafo juga dapat mengalami overload walaupun arus beban belum melebihi arus beban penuh dikarenakan suhu trafo sudah melebihi batas yang diijinkan. Tujuan dari penelitian ini adalah untuk mengetahui setiap perubahan suhu trafo dapat dipantau secara otomatis dengan tampilan HMI melalui software VTScada yang terhubung dengan Arduino Mega 2560 melalui ethernet shield dan router. Alat simulator ini telah dilakukan beberapa pengukuran dan pengujian cara pengoperasiannya. hasil perbandingan pengukuran suhu trafo dengan termometer pada beban 4 lampu $21 \mathrm{~W}$ dan 2 lampu $8 \mathrm{~W}$ terbaca arus 4,3 A dan rata-rata selisih error sebesar 1,32\%. Sehingga diharapkan alat ini dapat memberikan pengetahuan kepada masyarakat luas tentang sistem Monitoring suhu trafo dalam menjaga sistem transmisi tenaga listrik dengan baik dan mudah dimengerti.
\end{abstract}

Kata Kunci : VTScada, Arduino Mega 2560, Beban Lebih, Sensor Suhu

\begin{abstract}
Disturbance on the transformer can cause damage and decreased performance of the transformer. Examples of causes of damage to the transformer are overload and unbalanced loads. Overload occurs because the load mounted on the transformer exceeds the maximum capacity of the transformer where the load current exceeds the full load current of the transformer. The transformer may also be overloaded even though the load current has not exceeded the full load current since the transformer temperature has exceeded the allowable limit. The purpose of this research is to know every change of transformer temperature can be monitored automatically with HMI display through VTScada software connected with Arduino Mega 2560 via ethernet shield and router. This simulator has been done several measurements and testing the way of operation. the result of comparison of transformer temperature measurement with thermometer at load 4 lamp $21 \mathrm{~W}$ and 2 lamp read $8 \mathrm{~W}$ current $4.3 \mathrm{~A}$ and mean difference of error equal to $1,32 \%$. So it is expected this tool can provide knowledge to the public about the temperature monitoring system transformer in maintaining the electrical transmission system properly and easily understood.
\end{abstract}

Keywords: VTScada, Arduino Mega 2560, Overload, Temperature Sensor

\section{PENDAHULUAN}

Salah satu cara meningkatkan keadalan sistem tenaga listrik adalah dengan menjaga kontinyuitas penyaluran energi listrik[7]. Penyaluran energi listrik dengan menaikkan atau menurunkan tegangan harus melalui transformator tenaga. Trafo merupakan peralatan listrik yang sangat penting karena berhubungkan langsung dengan saluran transmisi dan distribusi listrik. Gangguan pada trafo dapat menyebabkan rusaknya dan menurunnya kinerja dari trafo. Contoh. Overload terjadi karena beban yang terpasang pada trafo melebihi kapasitas maksimum dari trafo dimana arus beban melebihi arus beban penuh dari trafo. Trafo juga dapat mengalami overload walaupun arus beban belum melebihi arus beban penuh dikarenakan suhu trafo sudah melebihi batas yang diijinkan. Selama ini di lapangan, pemeliharaan transformator dilakukan berdasarkan jadwal, sehingga tidak dapat dipantau dalam rentang waktu yang pendek, misalnya setiap hari dan itupun pekerja harus melihat langsung ke serandang. Akibatnya sulit mendeteksi gangguan pada tranformator secara dini.[2]

Berdasarkan kondisi dan kendala tersebut, maka dibutuhkan sistem monitoring kondisi transformator jarak 
jauh dan real-time. Parameter yang perlu dipantau untuk mengetahui kondisi transformator antara lain tegangan, arus, suhu transformator diimplementasikan pada prototipe ini.[3][4]

Pada penelitian ini, akan dibuat prototipe monitoring transformator tenaga dengan data logger dilengkapi HMI (Human Mechine Interface) untuk menampilkan hasil pengukuran, sehingga prototipe ini dapat memberi informasi kondisi transformator secara real-time ke operator Gardu Induk untuk mengetahui kondisi transformator yang mengalami gangguan secara cepat serta efisiensi tinggi. Prototipe disini dilengkapi berbagai macam proteksi berupa led indikator sebagai tanda trafo dalam keadaan aman sampai berbahaya, buzzer sebagai alarm apabila suhu melebihi batas, kipas sebagai pendingin trafo.

\section{Metode}

\subsection{Blok Diagram Sistem}

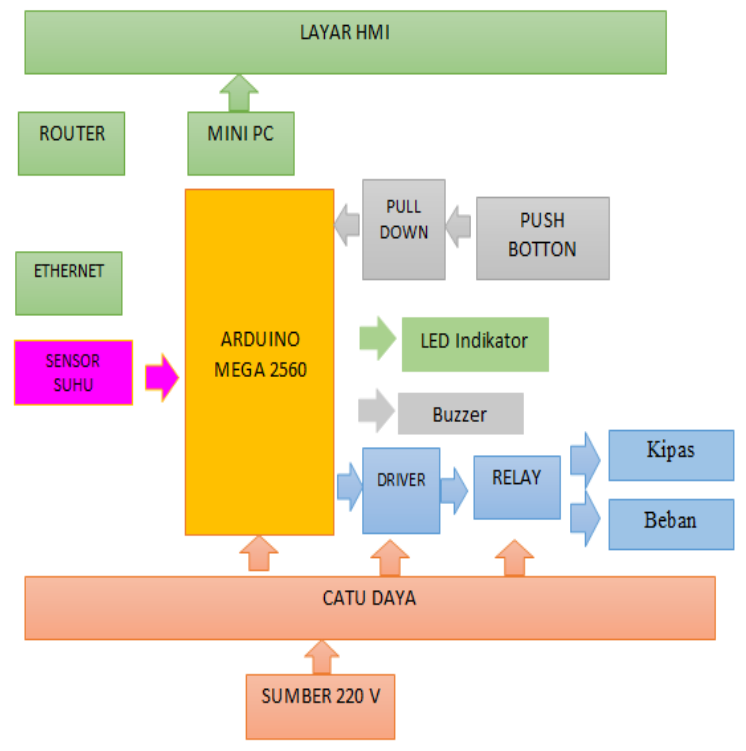

Gambar 1 Blok Diagram Sistem

\subsection{Power Supply Adaptor}

Arus Listrik yang kita gunakan di rumah, kantor dan pabrik pada umumnya adalah dibangkitkan, dikirim dan didistribusikan ke tempat masing-masing dalam bentuk Arus Bolak-balik atau arus AC (Alternating Current). Hal ini dikarenakan pembangkitan dan pendistribusian arus Listrik melalui bentuk arus bolak-balik (AC) merupakan cara yang paling ekonomis dibandingkan dalam bentuk arus searah atau arus DC (Direct Current). Akan tetapi, peralatan elektronika yang kita gunakan sekarang ini sebagian besar membutuhkan arus DC dengan tegangan yang lebih rendah untuk pengoperasiannya. Oleh karena itu, hampir setiap peralatan Elektronika memiliki sebuah rangkaian yang berfungsi untuk melakukan konversi arus listrik dari arus AC menjadi arus DC dan juga untuk menyediakan tegangan yang sesuai dengan rangkaian Elektronika-nya yang membentuk sebuah DC Power Supply atau Pencatu daya ini. Dibawah ini adalah Diagram Blok DC Power Supply (Adaptor) pada umumnya.

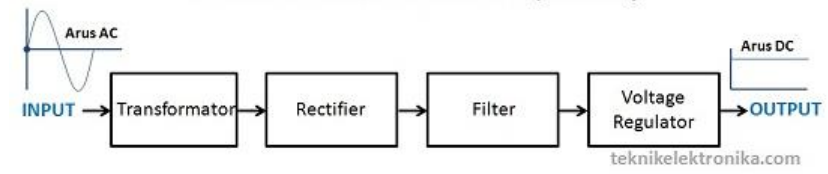

\section{Gambar 2. Blok Diagram Power Supply}

\subsection{Rangkaian Driver Relay}

Pada rangkaian driver relay ini, sistem menggunakan ULN2803 yang merupakan IC yang didalamnya terdapat 8 susunan transistor NPN yang terpasang darlington dapat mengalirkan arus sebesar $500 \mathrm{~mA}$ dan bekerja pada tegangan maksimal 50 Volt. Kemudian, untuk cara kerjanya yaitu memberi sinyal HIGH (1) atau LOW (0) pada output pin digital di arduino disambungkan ke IC ULN2803 yang merupakan beberapa transistor yang disusun kedalam sebuah IC dan terdiri dari 8 buah transistor NPN yang disusun Darlington.

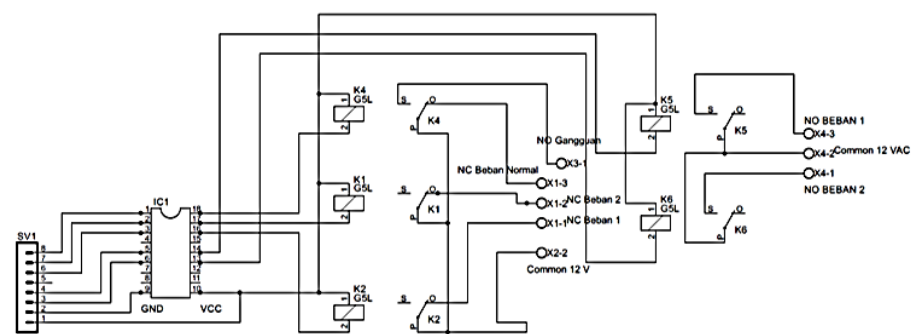

Gambar 3. Rangkaian Driver Relay

\subsection{Rangkaian Pull Down}

Resistor pull down digunakan untuk mengatasi floating pada push button dengan kondisi low. Pada rangkaian diatas saat switch button ditekan, maka input akan bernilai high. Kemudian, dengan menambahkan sebuah resistor menuju ground, yang dirangkai paralel dengan jalur yang menuju input pin Arduino Mega 2560, maka akan menghasilkan output yang high pula.

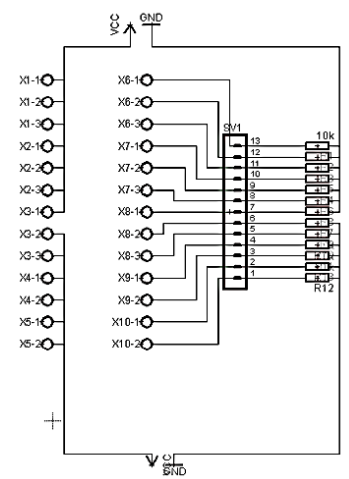

Gambar 4 Rangkaian Pull Down 


\subsection{Ethertnet Shield}

Pada penelitian ini, ethernet shield digunakan untuk menambah kemampuan Arduino Mega 2560 terhubung dengan SCADA menggunakan Modbus TCP/IP.

\subsection{Router}

Router pada penelitian ini berfungsi untuk menghubungkan Arduino Mega 2560 dengan PC (Personal Computer) melalui janringan TCP/IP.

\subsection{Cara Kerja Rangkaian}

\section{Flow Chart Sistem Kerja Alat}

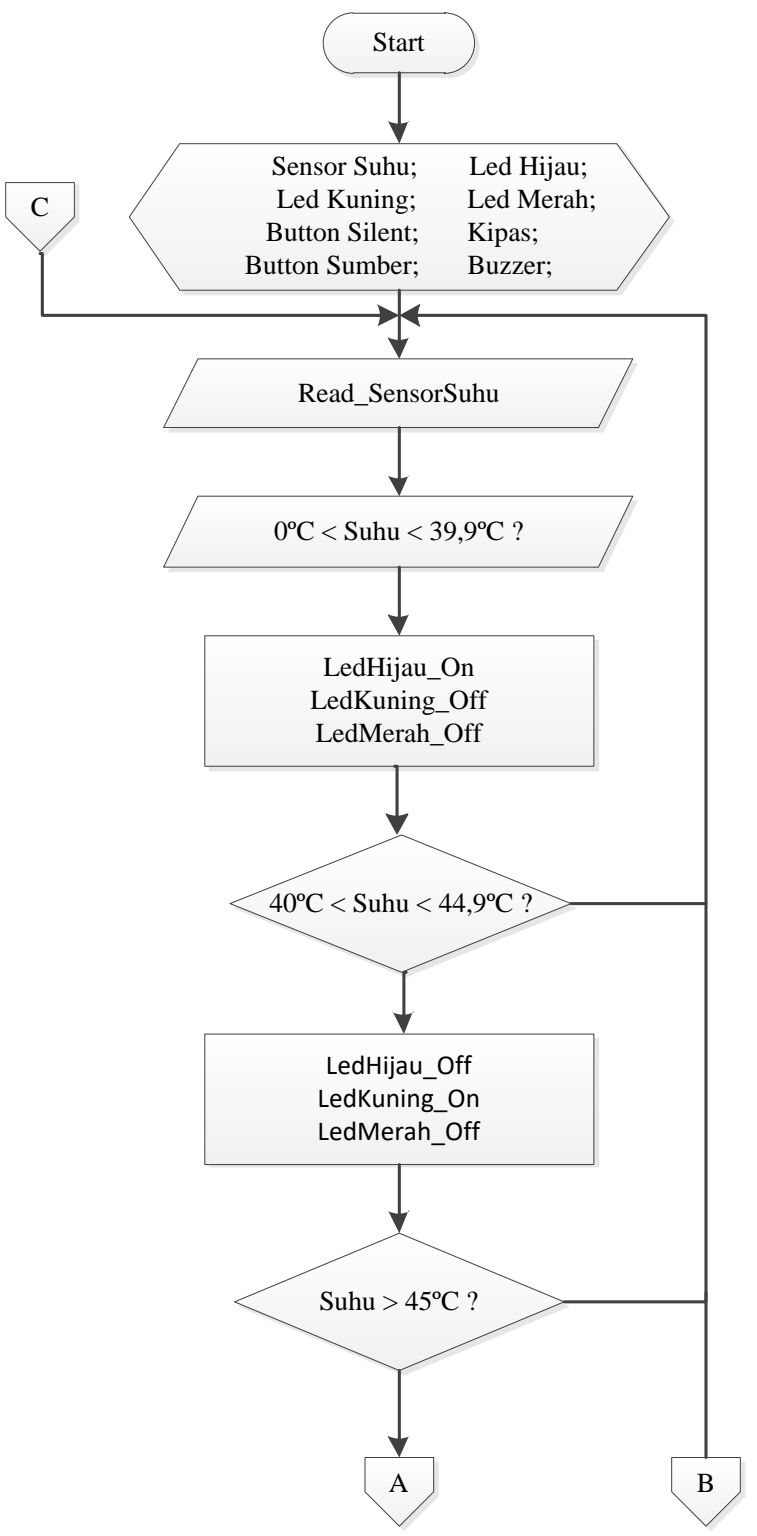

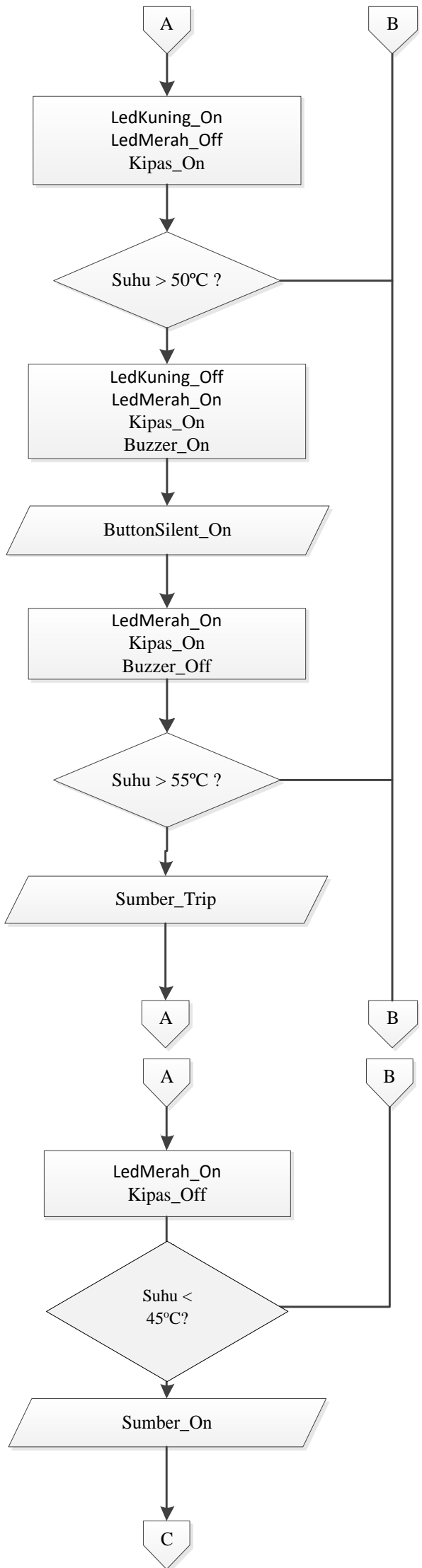

Gambar 5. Flowchart Prinsip Kerja Alat 


\section{Cara Kerja Rangkaian}

Pendeteksian suhu ini dilakukan oleh sensor suhu LM 35 yang 3 kaki LM 35 (VCC,Output,Ground) dimasukkan kedalam pin Arduino Mega 2560 untuk mengetahui hasil suhu yang terukur dengan pembacaan sebagai berikut :

1) Ketika suhu yang terukur $<40^{\circ} \mathrm{C}$ maka Arduino memerintah led hijau untuk on yang menandakan trafo dalam kondisi normal.

2) Ketika suhu yang terukur naik $>40^{\circ} \mathrm{C}$ dan kurang dari $50^{\circ} \mathrm{C}$, maka Arduino memerintahkan led merah untuk off dan led kuning untuk on yang menandakan trafo dalam kondisi waspada. Serta saat suhu mencapai > $45^{\circ} \mathrm{C}$ Arduino memerintahkan kipas untuk menyala, kipas akan menyala sampai sumber trip.

3) Selanjutnya saat suhu $>50^{\circ} \mathrm{C}$ Arduino memerintahkan led kuning untuk off dan led merah on yang menandakan trafo dalam kondisi berbahaya disertai berbunyi buzzer sebagai alarm peringatan.

4) Terakhir saat suhu sudah mencapai suhu maksimal sesuai setting yaitu suhu $>55^{\circ} \mathrm{C}$ Arduino secara otomatis memerintahkan sumber untuk trip. Dan sumber akan kembali menyala saat suhu sudah mulai turun $<45^{\circ} \mathrm{C}$ dan sistem kembali seperti semula sesuai settingnya.

Apabila trafo bekerja dengan keadaan panas dengan periode terus menerus, maka umur trafo tersebut bisa dipastikan tidak akan lama. Karena saat bekerja dengan keadaan panas, panas yang dihasilkan tersebut dapat merusak dari komponen-komponen trafo itu sendiri. Semua hasil pengukuran sensor suhu ditampilkan pada VTScada dan hasilnya tersimpan di Data Logger dalam bentuk Ms.Exel.

\section{Hasil \& Analisa}

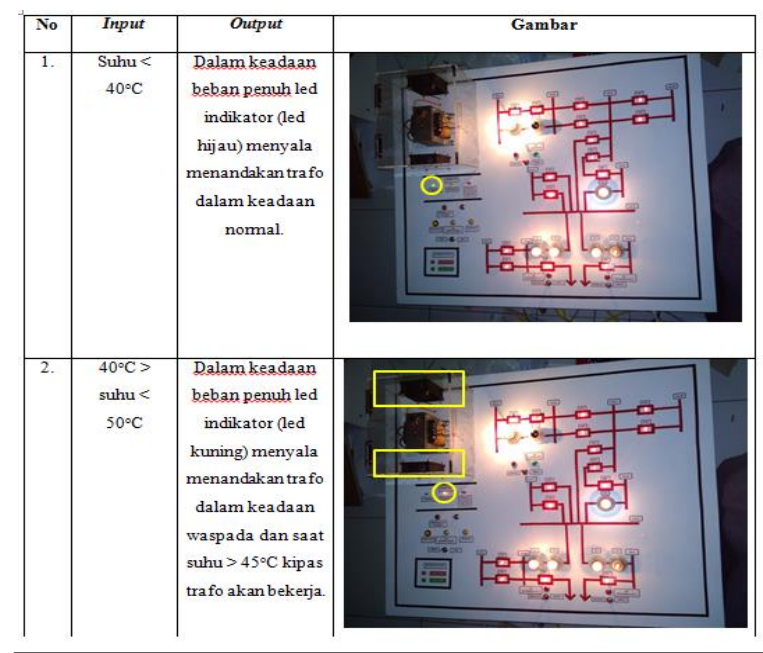

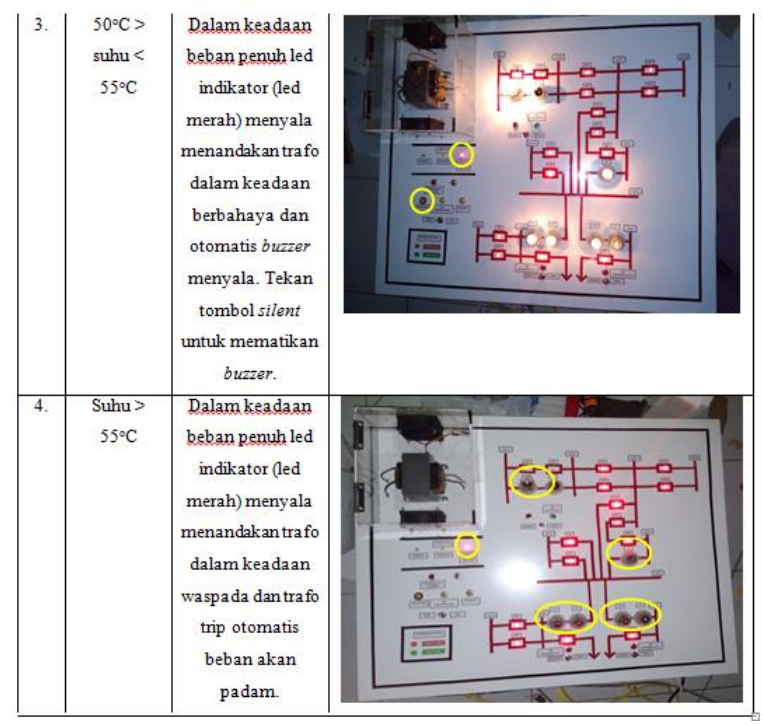

Gambar 6. Pengujian Alat

Tabel 1. Data Hasil Pengujian\

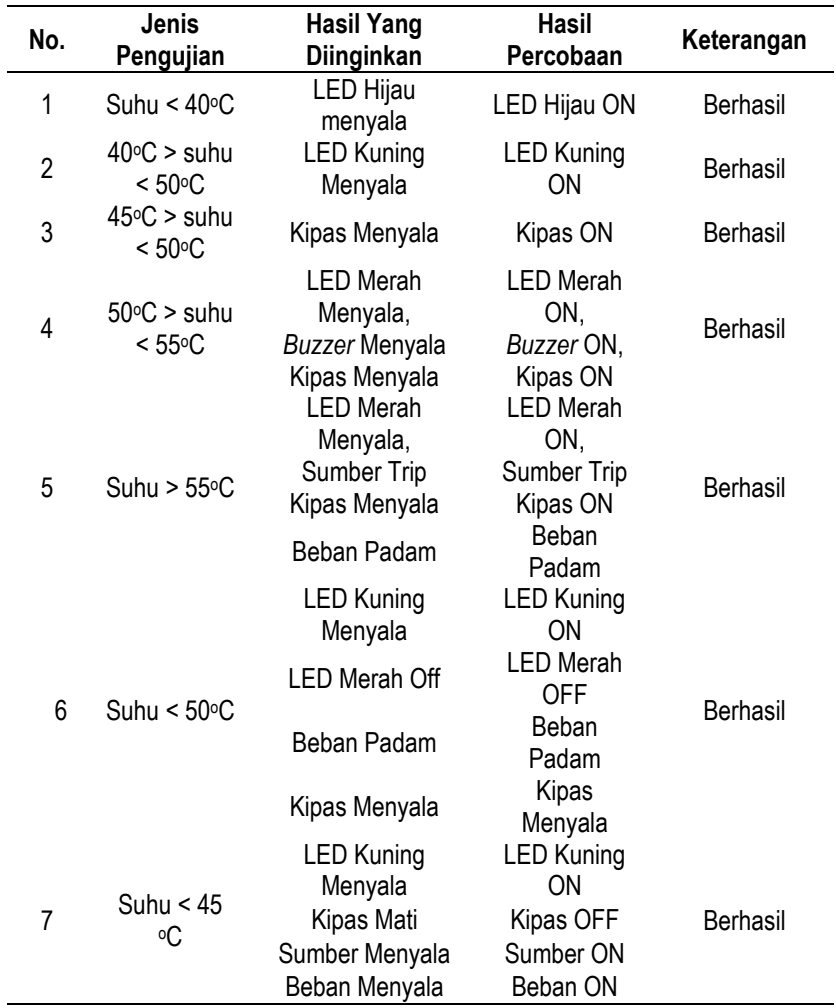

Dari data pengujian diatas dapat dihitung effisiensi kerja alat monitoring suhu trafo sebagai berikut:

Effisiensi = jumlahkeberhasilan/ jumlah pengujian

x $100 \%$

Effisiensi $\quad=7 / 7 \times 100 \%$

$=100 \%$ 
Tabel 2. Data Hasil Pengujian

\begin{tabular}{cccc}
\hline No & $\begin{array}{c}\text { Pengukuran } \\
\text { Suhu Trafo }\end{array}$ & $\begin{array}{c}\text { Pengukuran } \\
\text { Suhu } \\
\text { Termometer }\end{array}$ & $\begin{array}{c}\text { Error } \\
(\%)\end{array}$ \\
\hline 1. & $35^{\circ} \mathrm{C}$ & $35,6^{\circ} \mathrm{C}$ & 1,71 \\
2. & $36^{\circ} \mathrm{C}$ & $36,47^{\circ} \mathrm{C}$ & 1,30 \\
3. & $37^{\circ} \mathrm{C}$ & $37,35^{\circ} \mathrm{C}$ & 0,94 \\
4. & $38^{\circ} \mathrm{C}$ & $38,67^{\circ} \mathrm{C}$ & 1,76 \\
5. & $39{ }^{\circ} \mathrm{C}$ & $39,55^{\circ} \mathrm{C}$ & 1,41 \\
6. & $40^{\circ} \mathrm{C}$ & $40,43{ }^{\circ} \mathrm{C}$ & 1,07 \\
7. & $41^{\circ} \mathrm{C}$ & $41,75^{\circ} \mathrm{C}$ & 1,82 \\
8. & $42^{\circ} \mathrm{C}$ & $43,07^{\circ} \mathrm{C}$ & 2,54 \\
9. & $43^{\circ} \mathrm{C}$ & $43,51^{\circ} \mathrm{C}$ & 1,18 \\
10. & $44^{\circ} \mathrm{C}$ & $44,82^{\circ} \mathrm{C}$ & 1,86 \\
11. & $45^{\circ} \mathrm{C}$ & $45,43{ }^{\circ} \mathrm{C}$ & 0,95 \\
12. & $46{ }^{\circ} \mathrm{C}$ & $46,81^{\circ} \mathrm{C}$ & 1,76 \\
13. & $47^{\circ} \mathrm{C}$ & $47,12^{\circ} \mathrm{C}$ & 0,25 \\
14. & $48^{\circ} \mathrm{C}$ & $48,47^{\circ} \mathrm{C}$ & 0,97 \\
15. & $49{ }^{\circ} \mathrm{C}$ & $49,32^{\circ} \mathrm{C}$ & 0,65 \\
16. & $50^{\circ} \mathrm{C}$ & $50,63^{\circ} \mathrm{C}$ & 1,26 \\
17. & $51^{\circ} \mathrm{C}$ & $51,59^{\circ} \mathrm{C}$ & 1,15 \\
\hline
\end{tabular}

\section{Kesimpulan}

Dari perhitungan effisiensi kinerja alat keseluruhan yang mencapai $100 \%$ dapat disimpulkan bahwa alat bekerja baik dengan semestinya. Hasil pengujian-pengujian ini dapat membuktikan bahwa rangkaian keseluruhan alat dapat berjalan dengan normal dan baik sesuai setting alat.

Hasil perbandingan pengukuran LM35 dengan termometer dengan beban 4 lampu $21 \mathrm{~W}$ dan 2 lampu $8 \mathrm{~W}$ terbaca arus 4,2A dan rata-rata selisih error sebesar $1,32 \%$. Hal ini menandakan alat dalam kondisi baik dan berfungsi sebagai semestinya sesuai standar error yaitu dibawah $5 \%$.

Pada alat monitoring suhu trafo menggunakan Arduino Mega 2560 dan LM 35 dapat mendeteksi adanya perubahan suhu dengan berbagai macam indikator dan melakukan trip beban jika mencapai suhu maksimal dengan cepat dan baik.
Untuk pengaturan beban, dapat dilakukan melalui local maupun melalui layar HMI. Kedua cara ini sama-sama akan mengkontak relay yang terpasang pada sumber dan beban terlebih dahulu. Dan untuk mengkontaknya melalui perintah Arduino.

Simulasi SCADA pada alat ini juga sudah dapat membaca suhu yang terukur pada LM 35 dan hasil pengukuran dapat tersimpan data logger di Ms.Excel.

\section{Referensi}

[1]. PT PLN (Persero) Jasa Pendidikan dan Pelatihan. (2010). Monitoring Peralatan GI/GITET dan Sistem Pelaporan. Jakarta : PT.PLN (Persero).

[2]. PT PLN (Persero) P3B Jawa-Bali. (2013).Buku Pedoman Trafo Tenaga..Jakarta: PT PLN (Persero).

[3] Sensor Suhu LM $35 . \quad$ http://elektronikadasar.web.id/sensor-suhu-ic-lm35/. Diakses tanggal 01 Juli 2017

[4]. Andi, Hasad. 2011. Materi Kuliah Elektronika Industri. Jurnal Yang Dipublikasikan. Malang : UNISMA

[5]. Arduino \& Genuino Products. Arduino MEGA 2560 \& Genuino MEGA 2560.https://www.arduino.cc/en/Main/arduinoBoardMe ga2560. Diakses tanggal 17 Juni 2017.

[6]. Chapman. 2005. Electric Machinery Fundamentals 4th Edition. New York: McGraw-Hill.

[7]. Petruzella, D. Frank. 1996. Elektronika Industri. Yogyakarta : ANDI [1]. Setijasa, Hery. 2013. Proses dan Sistem Penyaluran Tenaga Listrik oleh PT. PLN (Persero). Semarang : Politeknik Negeri Semarang.

[8]. Marsudi, Djiteng. (2015). Operasi Sistem Tenaga Listrik. Jakarta: Graha Ilmu

[9]. PT PLN (Persero) Pusat Pendidikan dan Pelatihan. (2010). Peralatan Gardu Induk. Jakarta: PT PLN (Persero).

[10]. PT PLN (Persero) Pelatihan O\&M Relai Proteksi Gardu Induk. (2005). Sistem Proteksi. Jakarta: PT PLN (Persero) 